\title{
Gold nanoparticles decorated silicate sol-gel matrix embedded reduced graphene oxide and manganese ferrite nanocomposite- materials-modified electrode for glucose sensor application
}

\author{
T RAVINDRAN MADHURA, G GNANA KUMAR*(D) and RAMASAMY RAMARAJ*(D) \\ Department of Physical Chemistry, School of Chemistry, Centre for Photoelectrochemistry, Madurai Kamaraj \\ University, Madurai, Tamilnadu 625 021, India \\ E-mail: kumarg2006@gmail.com; ramarajr@yahoo.com
}

MS received 15 November 2018; revised 21 February 2019; accepted 3 March 2019; published online 25 April 2019

\begin{abstract}
Gold nanoparticles decorated on silicate sol-gel matrix embedded manganese ferrite $\left(\mathrm{MnFe}_{2} \mathrm{O}_{4}\right)$ reduced graphene oxide (rGO) nanocomposites were synthesized through a facile chemical method. The prepared samples were characterized by using powder X-ray diffraction (XRD), UV-vis absorption spectroscopy (UV-VIS), energy-dispersive X-ray spectroscopy (EDX), high-resolution transmission electron microscopy (HRTEM) and selected area electron diffraction (SAED) analyses. The Au nanostructures on rGO- $\mathrm{MnFe}_{2} \mathrm{O}_{4}$ improved the electrocatalytic activity of the rGO-MnFe ${ }_{2} \mathrm{O}_{4} @ \mathrm{Au}$ composite-materials-modified electrodes towards glucose oxidation. Cyclic voltammetry and amperometric methods were used to evaluate the electrocatalytic activity of the $\mathrm{rGO}-\mathrm{MnFe}_{2} \mathrm{O}_{4} @ \mathrm{Au}$ modified electrodes towards glucose oxidation in $0.1 \mathrm{M}$ $\mathrm{NaOH}$ at a less-positive potential $(0.2 \mathrm{~V})$ in the absence of any enzyme or redox mediator. The nanocompositemodified electrode (GCE/EDAS/rGO-MnFe $\mathrm{O}_{4} @ \mathrm{Au}$ ) was successfully used for the amperometric sensing of glucose and the experimental detection limit of $10 \mu \mathrm{M}$ glucose was observed. The common interfering agents did not interfere with the detection of glucose. The present sensor showed good stability, reproducibility, and selectivity. The nanocomposite-modified electrode was successfully used for the determination of glucose in the urine sample.
\end{abstract}

Keywords. Manganese ferrite; reduced graphene oxide; gold nanostructures; modified electrode; glucose.

\section{Introduction}

Manganese ferrite $\left(\mathrm{MnFe}_{2} \mathrm{O}_{4}\right)$, an eco-friendly material with favorable capacitive characteristics, is a suitable material for a wide range of applications such as Li-ion batteries, heterogeneous catalysts, gas sensors, etc. ${ }^{1-6}$ Though the ferrites are advantageous in the development of catalysis, certain limitations including defects, mechanical instability, poor electronic conductivity significantly impede them from wide applications in catalysis with high sensitivity, fast response and reliability. ${ }^{7}$ Considering the aforesaid issues, it is important to enhance the charge transport ability of ferrites by coupling them with highly conducting materials, such as single and multi-walled carbon nanotubes (CNTs), noble metal nanoparticles and graphene. ${ }^{8}$ Based on the study, graphene has received considerable attention among other carbon supports as an attractive 2D supporting material owing to its high surface area, excellent thermal and electrical properties, high elastic behavior and extended charge carrier mobility. Graphite oxide and graphene oxide (GO) are the derivatives of graphene that can be used as carbon supports. The reduced GO (rGO) exhibits superior electrocatalytic properties efficiently over bare GO due to the restoration of a graphitic network of $\mathrm{sp}^{2}$ bonds and makes it a promising material for catalysis. The rGO is usually obtained from graphene oxide by reduction. ${ }^{9,10}$ Recently, there were many studies about reduced graphene oxide-based metal oxides such as copper oxide, ${ }^{11}$ nickel oxide ${ }^{12}$ and cobalt

\footnotetext{
*For correspondence

Electronic supplementary material: The online version of this article (https://doi.org/10.1007/s12039-019-1611-z) contains supplementary material, which is available to authorized users.
} 
oxide $^{13}$ and they have been used in electrochemical sensors for glucose. To increase the catalytic activity of graphene-based metal oxide, it has been decorated with highly catalytic gold nanostructures (Au NSs) which increases the catalytic activity due to their unique chemical and physical properties, good biocompatibility and chemical stability. The amine functionalized silicate sol-gel matrix serves a multifunctional role such as reducing agent and stabilizing agent for the formation of Au NSs. ${ }^{14,15}$ The amine functionalized silicate matrix interacts with the rGO-metal oxides due to the presence of the amine groups. ${ }^{16,17}$

The vital need for glucose detection has attracted widespread attention in the food industry, fermentation industry, biochemistry, clinical diagnosis and environmental protection. Therefore, it is important to develop a stable, sensitive, selective and reliable nonenzymatic electrochemical sensor due to the inherent problems associated with enzymes-based sensor. ${ }^{18}$ The non-enzymatic electrochemical sensing of glucose is generally based on the direct electrocatalytic oxidation of glucose on the surface of active electrode material. ${ }^{19}$ Consequently, advances in the direct electrochemical oxidation of glucose with high sensitivity and selectivity are greatly desired.

Here, a facile method for the synthesis of rGO$\mathrm{MnFe}_{2} \mathrm{O}_{4}$ was developed by hydrothermal method. Further, the $\mathrm{rGO}-\mathrm{MnFe}_{2} \mathrm{O}_{4}$ was decorated with the $\mathrm{Au} \mathrm{NSs}$ via chemical synthesis method, carried out by treating amine functionalized silicate sol-gel matrix embedded $\mathrm{rGO}-\mathrm{MnFe}_{2} \mathrm{O}_{4}$ with $\mathrm{HAuCl}_{4}$ in aqueous solution at room temperature. The rGO sheets could be used as a template for the direct growth of $\mathrm{MnFe}_{2} \mathrm{O}_{4}$ to form an $\mathrm{rGO}-\mathrm{MnFe}_{2} \mathrm{O}_{4}$. Both the electrical conductivity and surface area of the composite can be increased greatly, thus making the rGO- $\mathrm{MnFe}_{2} \mathrm{O}_{4}$ to be better support for $\mathrm{Au} \mathrm{NSs}$ compared to the pure $\mathrm{MnFe}_{2} \mathrm{O}_{4}$ and rGO. An enzyme-less glucose sensor was constructed by using the EDAS/rGO- $\mathrm{MnFe}_{2} \mathrm{O}_{4} @ \mathrm{Au}$ nanocomposite material. Assisting from their unique structural and functional properties of different components and synergistic effect, the resulting EDAS/rGO- $\mathrm{MnFe}_{2} \mathrm{O}_{4} @ \mathrm{Au}$ nanocomposites-modified electrode showed enhanced electrocatalytic activity, high sensitivity and low limit of detection toward glucose sensing.

\section{Experimental}

\subsection{Materials and methods}

Graphite powder was purchased from Alfa Aesar. Manganese chloride tetrahydrate, ferric chloride hexahydrate, potassium permanganate $\left(\mathrm{KMnO}_{4}\right)$ and sulphuric acid $\left(\mathrm{H}_{2} \mathrm{SO}_{4}\right)$ were received from Alfa Aesar. Sodium hydroxide $(\mathrm{NaOH})$ was obtained from Merck. N-[3-(Trimethoxysilyl) propyl]-ethylenediamine (EDAS), glucose and gold(III) chloride trihydrate were from Sigma-Aldrich. All the solutions were prepared by using doubly distilled water. All the reagents were used as received without further purification. Absorption spectra were recorded on an Agilent Technologies 8453 spectrophotometer by using $1 \mathrm{~cm}$ quartz cell. The powder X-ray diffraction patterns were recorded by using a Bruker AXS D8 diffractometer with $\mathrm{Cu} \mathrm{K} \alpha$ radiation $(\lambda=$ $0.15418 \mathrm{~nm}$ ) operating at $40 \mathrm{kV}$ and $30 \mathrm{~mA}$. The purity and the chemical composition of the prepared composites were analyzed by energy-dispersive X-ray spectroscopy (EDX). High-resolution transmission electron microscopy (HRTEM) images were obtained by using JEOL JEM 2100 instrument operating at $200 \mathrm{kV}$.

\subsection{Synthesis of EDAS/rGO-MnFe $\mathrm{O}_{4} @ \mathrm{Au}$ nanocomposites}

GO was synthesized from graphite powder by following the modified Hummers method as described elsewhere. ${ }^{20}$ The rGO- $\mathrm{MnFe}_{2} \mathrm{O}_{4}$ nanocomposite was synthesized through onepot hydrothermal method, in which the reduction of $\mathrm{GO}$ and the in situ formation of $\mathrm{MnFe}_{2} \mathrm{O}_{4}$ nanosheets occurred simultaneously (detailed experimental procedure is discussed in Supplementary Information). The rGO- $\mathrm{MnFe}_{2} \mathrm{O}_{4}$ was amine functionalized by using EDAS silane. The silicate sol-gel (SSG) matrix embedded rGO- $\mathrm{MnFe}_{2} \mathrm{O}_{4} @ \mathrm{Au}(\mathrm{Au}=1,2$ and $3 \mathrm{mM}$ ) was prepared by using the following procedure. Briefly, $5 \mathrm{mg}$ of $\mathrm{rGO}-\mathrm{MnFe}_{2} \mathrm{O}_{4}$ was added to $5 \mu \mathrm{L}$ of $1 \mathrm{M}$ EDAS silane in $5 \mathrm{~mL}$ of water and sonicated for 30 min followed by vigorous stirring. The EDAS/rGO-MnFe $\mathrm{O}_{4}$ was obtained after $1 \mathrm{~h}$. To this resulting solution, different concentrations of $\mathrm{HAuCl}_{4}$ ( 1 or 2 or $3 \mathrm{mM}$ final concentration) was added and stirred for $12 \mathrm{~h}$. The formation of the brownish wine-red color solution indicated the formation of Au NSs at the composite. The aqueous mixture was centrifuged and washed three times with water and redispersed into $5 \mathrm{~mL}$ of water. The EDAS SSG was used as a capping as well as a reducing agent. For comparison studies, EDAS/ $/ \mathrm{MnFe}_{2} \mathrm{O}_{4} @ \mathrm{Au}, \mathrm{EDAS} / \mathrm{rGO} @ \mathrm{Au}$, and EDAS/rGO- $\mathrm{MnFe}_{2} \mathrm{O}_{4}$ were prepared by using a similar procedure. The schematic representation of the preparation of EDAS/rGO- $\mathrm{MnFe}_{2} \mathrm{O}_{4} @ \mathrm{Au}$ nanocomposite is given in Scheme 1A.

\subsection{Electrochemical experiment}

Electrochemical experiments were carried out by using a single compartment, a three-electrode cell with EDAS/rGO$\mathrm{MnFe}_{2} \mathrm{O}_{4} @$ Au nanocomposites-modified glassy carbon electrode (GCE) and dia $3 \mathrm{~mm}$ as working electrode, a platinum wire as an auxiliary electrode, and an $\mathrm{Ag} / \mathrm{AgCl} / \mathrm{Cl}^{-}(1 \mathrm{M}$ $\mathrm{KCl})$ as reference electrode under a nitrogen atmosphere. The measurements were performed at room temperature by using a CH Instruments Electrochemical Workstation (Model-760D). 


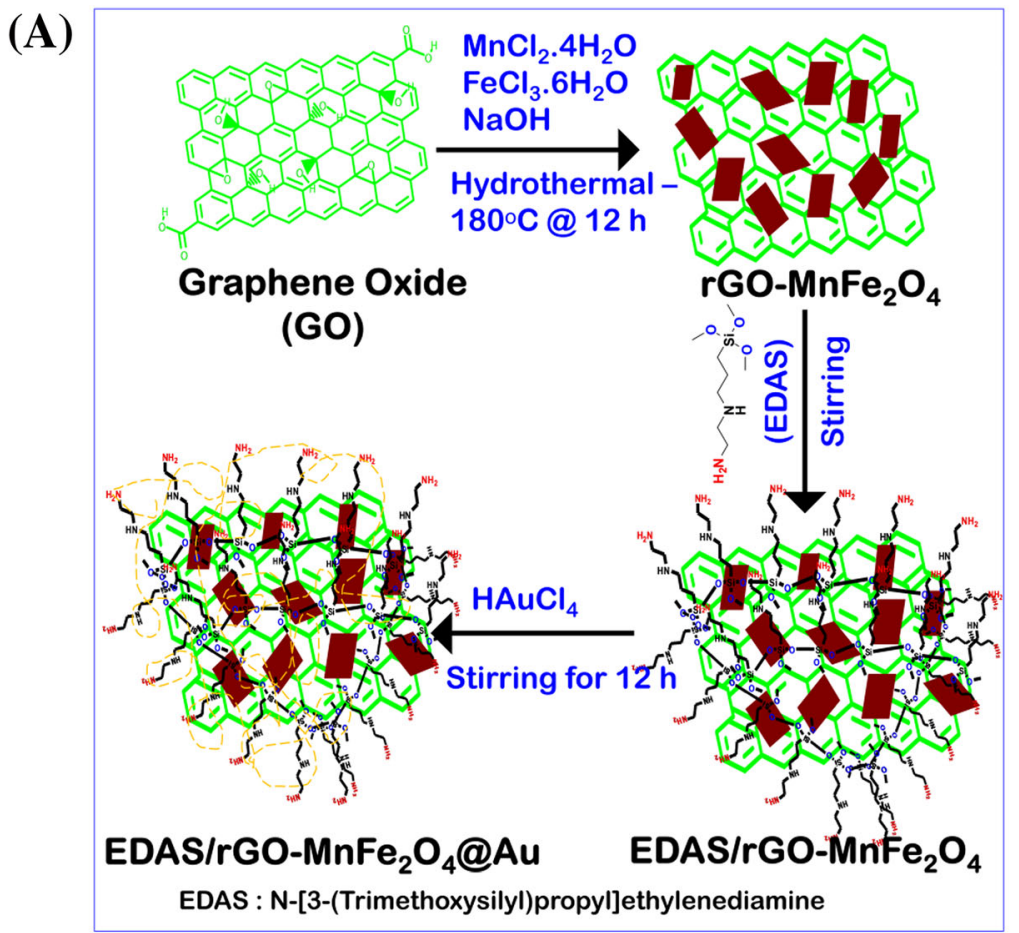

(B)

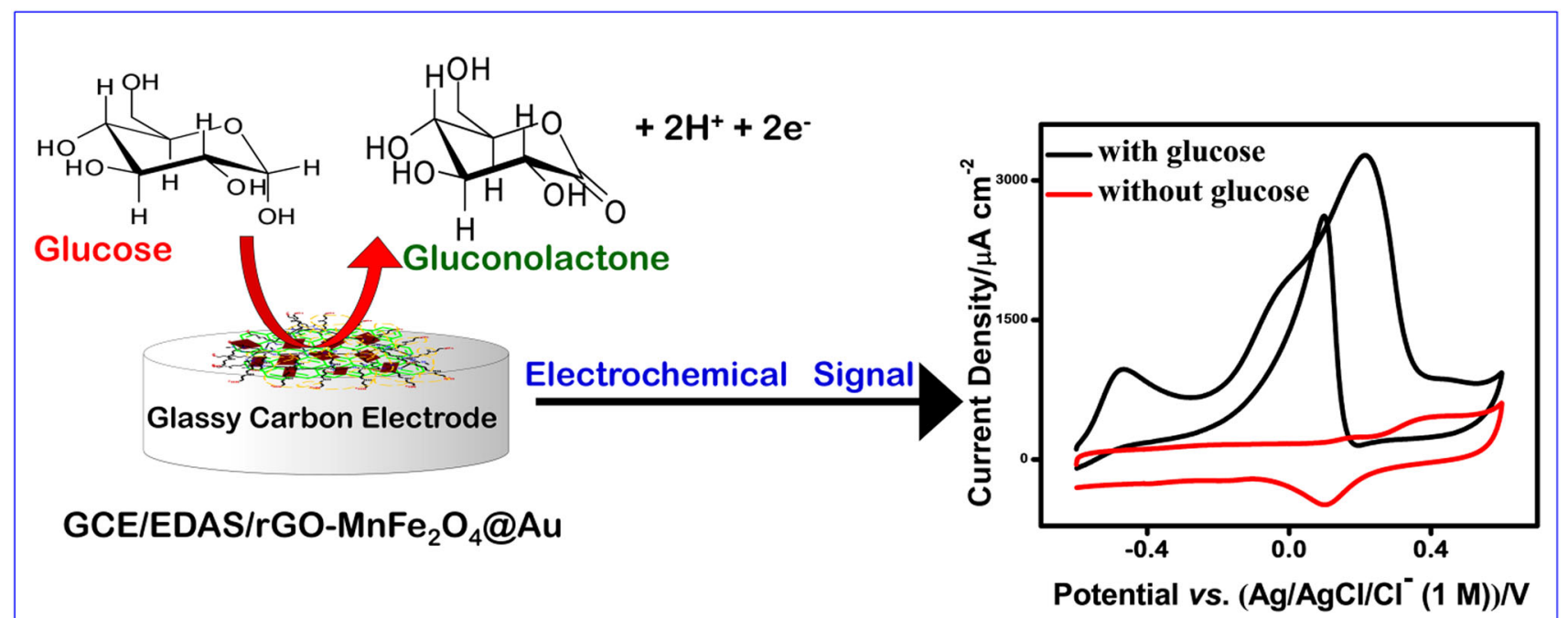

Scheme 1. (A) Schematic representation of the preparation of EDAS/rGO- $\mathrm{MnFe}_{2} \mathrm{O}_{4} @$ Au nanocomposite material. (B) Schematic representation of the electrocatalytic oxidation of glucose at the EDAS/rGO-MnFe ${ }_{2} \mathrm{O}_{4} @ \mathrm{Au}$ nanocomposite modified GCE in $0.1 \mathrm{M} \mathrm{NaOH}$ at a scan rate of $50 \mathrm{mV} / \mathrm{s}$.

A $0.1 \mathrm{M} \quad \mathrm{NaOH}$ solution was used as supporting electrolyte and the sensing studies were carried out with the successive addition of glucose solution. A $5 \mu \mathrm{L}$ of EDAS/ rGO-MnFe $\mathrm{O}_{4} @ \mathrm{Au}$ was dropped on a cleaned GCE (polished with 1.0, 0.3 and $0.05 \mu \mathrm{m}$ alumina). Then the solvent of the slurry was slowly evaporated at room temperature. The schematic illustration of electrochemical oxidation of glucose using the nanocomposite material modified electrode is shown in Scheme 1B.

\section{Results and Discussion}

\subsection{Spectral study of EDAS/rGO-MnFe ${ }_{2} \mathrm{O}_{4} @ \mathrm{Au}$ nanocomposites}

The formation of EDAS/rGO- $\mathrm{MnFe}_{2} \mathrm{O}_{4} @$ Au nanocomposite materials was primarily confirmed by the absorption spectroscopy. The absorption spectra of the EDAS/MnFe $\mathrm{O}_{4} @ \mathrm{Au}-2, \mathrm{EDAS} / \mathrm{rGO} @ \mathrm{Au}-2$, and 


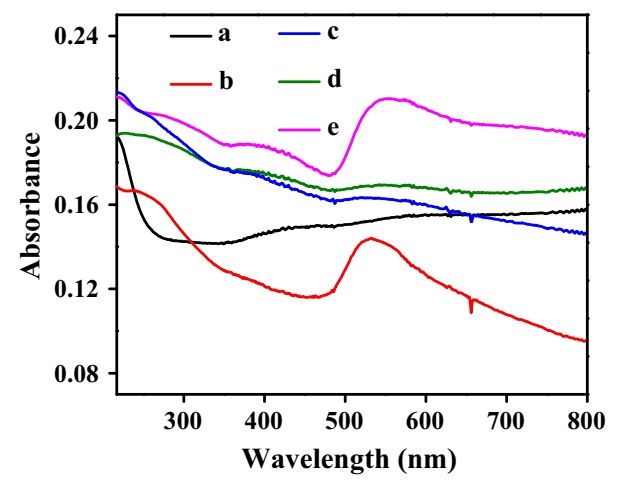

Figure 1. Absorption spectra of EDAS/ $\mathrm{MnFe}_{2} \mathrm{O}_{4} @ \mathrm{Au}-2$ (a), EDAS/rGO@Au-2 (b), EDAS/rGO-MnFe $2 \mathrm{O}_{4} @ \mathrm{Au}-1$ (c), EDAS/rGO-MnFe $2 \mathrm{O}_{4} @ \mathrm{Au}-2$ (d) and EDAS/rGO-MnFe $2 \mathrm{O}_{4} @ \mathrm{Au}-3$ (e).

EDAS/rGO- $\mathrm{MnFe}_{2} \mathrm{O}_{4} @ \mathrm{Au}(\mathrm{Au}=1,2$ and $3 \mathrm{mM})$ nanocomposites were recorded and shown in Figure 1. The EDAS/ $/ \mathrm{MnFe}_{2} \mathrm{O}_{4} @ \mathrm{Au}-2$ showed a broad absorption band at $440 \mathrm{~nm}$ (Figure 1a) originating from the intrinsic band-edge absorption of $\mathrm{MnFe}_{2} \mathrm{O}_{4}{ }^{21}$ and the surface plasmon resonance (SPR) band due to the Au NS around $550 \mathrm{~nm}$ was also observed. ${ }^{22}$ The band observed in EDAS/rGO@Au-2 was red-shifted to $268 \mathrm{~nm}$ (Figure 1b) due to the disappearance of $\mathrm{C}=\mathrm{O}$ groups in $\mathrm{GO}$, ensuring the reduction of $\mathrm{GO}$ to rGO during the hydrothermal treatment. In addition, the SPR band of Au NSs was observed at around $530 \mathrm{~nm}$ for EDAS/rGO@Au-2 the nanocomposite. ${ }^{23}$ The EDAS/rGO-MnFe ${ }_{2} \mathrm{O}_{4} @ \mathrm{Au}-1$ nanocomposite (Figure 1c) showed a typical SPR absorption band for $\mathrm{Au}$ NSs at $525 \mathrm{~nm}$ with a characteristic band for rGO and $\mathrm{MnFe}_{2} \mathrm{O}_{4}$ around 260 and $400 \mathrm{~nm}$, respectively. The absorption band at $525 \mathrm{~nm}$ was observed due to the formation of spherical Au nanoparticles (NPs). The SPR band can be tuned by varying the particle size, shape as well as the surrounding dielectric medium of the Au NSs. When the concentration of Au increased to 2 and 3 $\mathrm{mM}$ (Figure 1( $\mathrm{d}$ and e ) ) the SPR band was red-shifted to around 540 and $552 \mathrm{~nm}$, respectively, which is indicative of the formation of Au network structure or larger size particles. $^{24}$

\subsection{HRTEM characterization of EDAS/rGO-MnFe $\mathrm{O}_{2} @$ @ Au nanocomposites}

To evaluate the morphology of EDAS/rGO- $\mathrm{MnFe}_{2} \mathrm{O}_{4} @$ Au nanocomposites the HRTEM images were recorded. Representative HRTEM images shown in Figure 2 reveal the morphologies of EDAS/rGO- $\mathrm{MnFe}_{2} \mathrm{O}_{4} @ \mathrm{Au}$ nanocomposites prepared with the different concentrations of Au. The HRTEM image of GO and $\mathrm{MnFe}_{2} \mathrm{O}_{4}$ shown in Figure 2a, b. The HRTEM image (Figure 2c) of the $\mathrm{rGO} / \mathrm{MnFe}_{2} \mathrm{O}_{4}$ reveals that the nanosheet-like $\mathrm{MnFe}_{2} \mathrm{O}_{4}$ structures are highly dispersed on the rGO sheets. Thus, the nanocomposite material prevented itself the aggregation and restacking of the $\mathrm{MnFe}_{2} \mathrm{O}_{4}$ and the $\mathrm{rGO}$ sheets, respectively. The EDAS/rGO-MnFe ${ }_{2} \mathrm{O}_{4} @ \mathrm{Au}-1$ shows the formation of spherical Au NPs which are accommodated on the EDAS/rGO- $\mathrm{MnFe}_{2} \mathrm{O}_{4}$ composite (Figure 2d). When the concentration of $\mathrm{Au}$ was increased to $2 \mathrm{mM}$ (Figure 2e), the morphology of the Au spherical NPs changed to Au network structure and in addition, some nanoparticles were found to be smaller in size on the surface. The presence of these Au network structures resulting in a shift in the absorption at $540 \mathrm{~nm}$ in the absorption spectrum was observed (Figure 1d). When the concentration was increased to $3 \mathrm{mM}$, it was found that the Au nanostructures got aggregated to give larger particles owing to the increased population of Au (Figure 2f). The dspacing value of $0.235 \mathrm{~nm}$ observed for the EDAS/rGO$\mathrm{MnFe}_{2} \mathrm{O}_{4} @ \mathrm{Au}-2$ nanocomposite showed the $\left(\begin{array}{lll}1 & 1 & 1\end{array}\right)$ crystal plane of $\mathrm{Au}$ (Figure $2 \mathrm{~g}$ ). To further confirm the structure of the obtained nanocomposite, typical SAED pattern of the EDAS/rGO-MnFe ${ }_{2} \mathrm{O}_{4} @ \mathrm{Au}-2$ nanocomposite is shown (inset of Figure 2f). The SAED pattern of Au showed the face-centred cubic crystal structure of $\mathrm{Au}$ and the calculated distances 0.25, 0.22, 0.14 and 0.12 $\mathrm{nm}$ agree well with the values reported in literature ${ }^{25}$ for (111), (200), (220) and (311) planes of Au, respectively (JCPDS File No. 04-0783). The EDX analyses of (Figure 2h) $\mathrm{rGO} / \mathrm{MnFe}_{2} \mathrm{O}_{4} @ \mathrm{Au}-2$ reveal that the presence of the individual elemental composition of carbon, oxygen, $\mathrm{Au}, \mathrm{Mn}$ and $\mathrm{Fe}$ on EDAS/rGO/MnFe $\mathrm{O}_{4} @ \mathrm{Au}-2$.

\subsection{XRD analyses of EDAS/rGO-MnFe $\mathrm{O}_{4} @ \mathrm{Au}$ nanocomposite}

The formation and crystalline nature of the Au nanoparticles present in the EDAS/rGO- $\mathrm{MnFe}_{2} \mathrm{O}_{4}$ nanocomposites prepared using different concentrations of $\mathrm{Au}$ were studied by XRD analysis (Figure 3 ). The XRD spectrum of EDAS/ $\mathrm{MnFe}_{2} \mathrm{O}_{4} @ \mathrm{Au}-2$ (Figure 3(a)) shows the well-defined diffraction peaks at the $2 \theta$ values of $35.07,56.5,65.9^{\circ}$ and $78.4^{\circ}$ which are indexed to (3 1 1), (5 11 1), (4 40 ) and (4 4 4) crystal plane reflections of spinel-type $\mathrm{MnFe}_{2} \mathrm{O}_{4}$, respectively (JCPDS 73-1964). ${ }^{26}$ The three diffraction peaks that appeared at $38.8^{\circ}, 44.9^{\circ}$ and $61.9^{\circ}$ are indexed to the (111), $\left(\begin{array}{lll}2 & 0 & 0\end{array}\right)$ and (2 2 0) diffraction planes of $\mathrm{Au}$, respectively (JCPDS 04-0783). ${ }^{27}$ In addition to the characteristic peaks for $\mathrm{MnFe}_{2} \mathrm{O}_{4}$ and $\mathrm{Au}$, a slight hump around $2 \theta$ value of $26.5^{\circ}$ (Figure 3(b-d)) was observed due to the presence of rGO in the nanocomposites. ${ }^{28}$ Thus the XRD results 


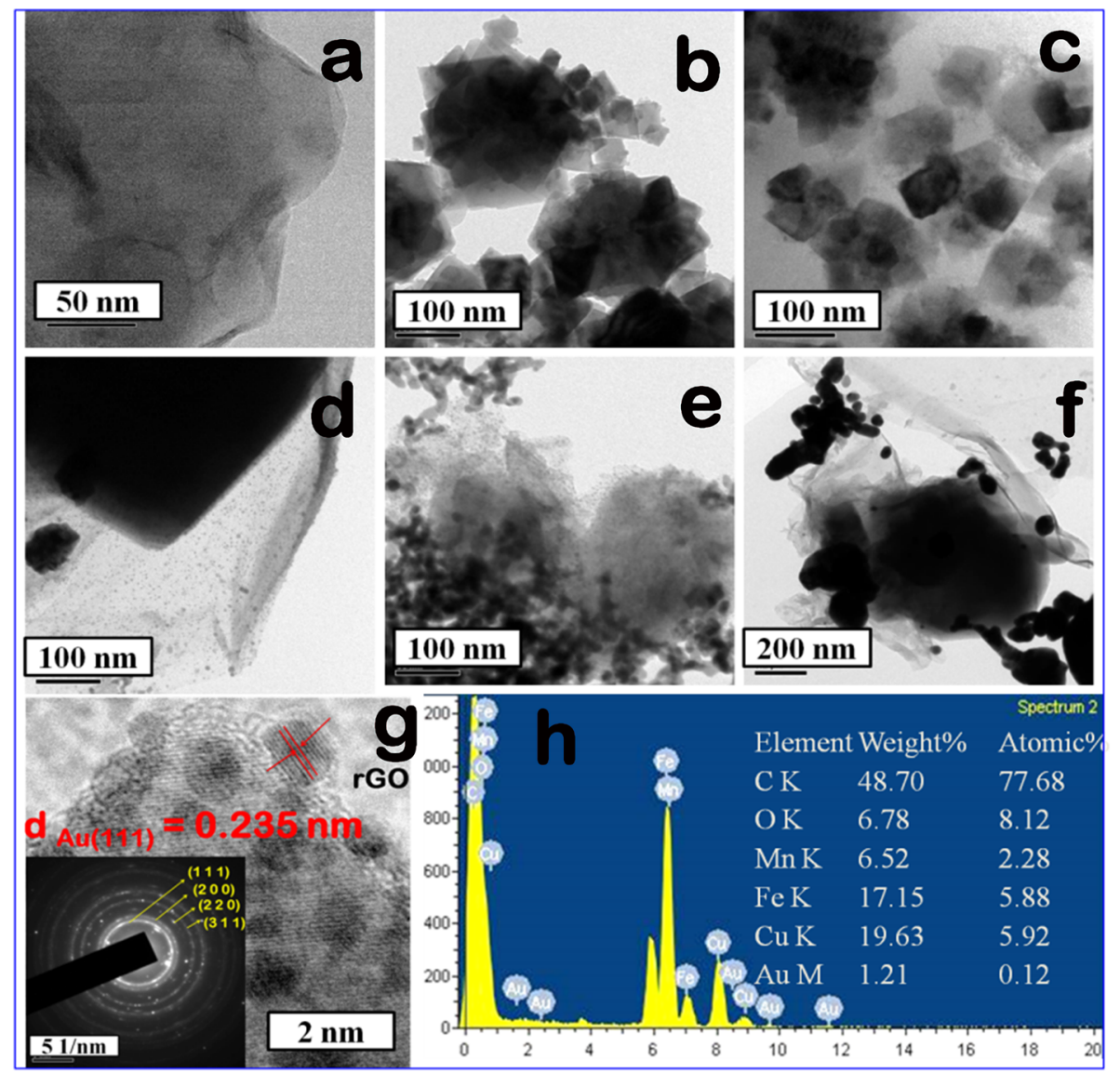

Figure 2. HRTEM images of $\mathrm{GO}$ (a), $\mathrm{MnFe}_{2} \mathrm{O}_{4}$ (b), $\mathrm{rGO}-\mathrm{MnFe}_{2} \mathrm{O}_{4}$ (c), EDAS/ rGO-MnFe ${ }_{2} \mathrm{O}_{4} @ \mathrm{Au}-1$ (d), EDAS/rGO-MnFe $2 \mathrm{O}_{4} @ \mathrm{Au}-2$ (e), EDAS/rGO-MnFe 2 $\mathrm{O}_{4} @ \mathrm{Au}-3$ (f), lattice fringes of EDAS/rGO-MnFe $2 \mathrm{O}_{4} @ \mathrm{Au}-2$ (g) and EDX of EDAS/rGO-MnFe $\mathrm{O}_{4} @ \mathrm{Au}-2$. Inset (Figure 2g): SAED pattern of EDAS/ rGO-MnFe $2 \mathrm{O}_{4} @ \mathrm{Au}-2$.

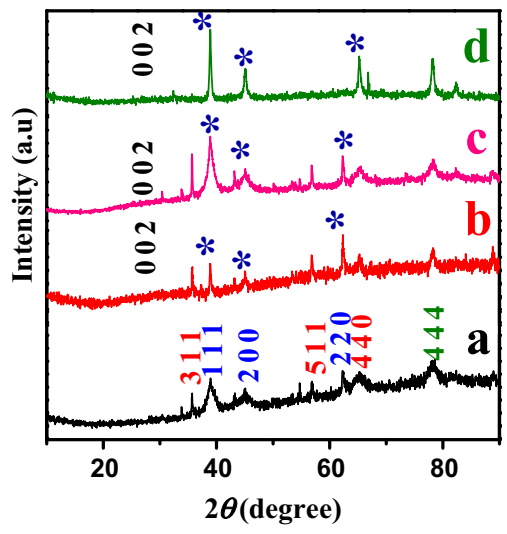

Figure 3. XRD patterns obtained for $\mathrm{EDAS} / \mathrm{MnFe}_{2} \mathrm{O}_{4} @ \mathrm{Au}-2$ (a),EDAS/rGO-MnFe $2 \mathrm{O}_{4} @ \mathrm{Au}-1$ (b), ED$\mathrm{AS} / \mathrm{rGO}-\mathrm{MnFe}_{2} \mathrm{O}_{4} @ \mathrm{Au}-2$ (c) and EDAS/rGO-MnFe $2 \mathrm{O}_{4} @ \mathrm{Au}-3$ (d).

confirm the formation of crystalline Au nanostructures on the EDAS/rGO- $\mathrm{MnFe}_{2} \mathrm{O}_{4}$ composite and the integration of individual component in the nanocomposite.
These d-spacing values and the obtained crystal planes from XRD data were found to be in good agreement with the SAED data.

\subsection{Electrocatalytic oxidation of glucose}

3.4a Voltammetric studies of glucose oxidation at GCE/EDAS/rGO-MnFe ${ }_{2} \mathrm{O}_{4} @ \mathrm{Au}$-2: To examine the electrocatalytic performance of the prepared EDAS/ rGO- $\mathrm{MnFe}_{2} \mathrm{O}_{4} @ \mathrm{Au}$ nanocomposite materials, the cyclic voltammetric $(\mathrm{CV})$ experiment was performed to study the oxidation of glucose. Figure 4A exhibits the $\mathrm{CV}$ curves recorded at the bare GCE (a), GCE/EDAS/ rGO-MnFe ${ }_{2} \mathrm{O}_{4}$ (b), GCE/EDAS/rGO (c), GCE/EDAS/ $\mathrm{MnFe}_{2} \mathrm{O}_{4}$ (d), GCE/EDAS/rGO@ Au-2 (e), GCE/EDAS $/ \mathrm{MnFe}_{2} \mathrm{O}_{4} @ \mathrm{Au}-2$ (f) and GCE/EDAS/rGO-MnFe $\mathrm{O}_{4} @$ $\mathrm{Au}-2$ (g) for $5 \mathrm{mM}$ glucose in $0.1 \mathrm{M} \mathrm{NaOH}$ at a scan rate of $50 \mathrm{mV} / \mathrm{s}$, which is a suitable medium for gold based non-enzymatic glucose sensors. ${ }^{29}$ Bare GCE, GCE/EDAS/rGO and GCE/EDAS/ $/ \mathrm{MnFe}_{2} \mathrm{O}_{4}$ did not show any characteristic voltammetric signal for the 

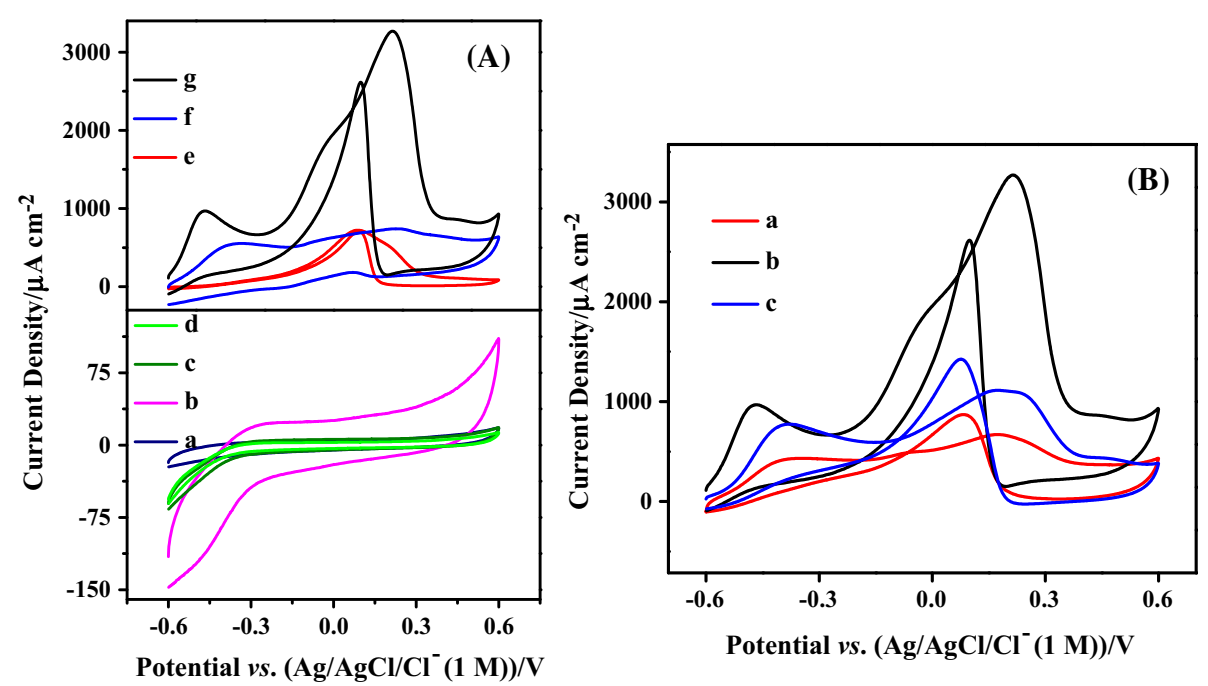

Figure 4. (A) $\mathrm{CVs}$ recorded for $5 \mathrm{mM}$ glucose in $0.1 \mathrm{M} \mathrm{NaOH}$ with a scan rate of $50 \mathrm{mV} \mathrm{s}^{-1}$ at (A): bare GCE (a), GCE/EDAS/rGO-MnFe ${ }_{2} \mathrm{O}_{4}$ (b), GCE/EDAS/rGO (c), GCE/EDAS/MnFe $2 \mathrm{O}_{4}$ (d), GCE/EDAS/rGO (e), GCE/EDAS/MnFe $\mathrm{O}_{4} @ \mathrm{Au}-2$ (f) and GCE/EDAS/rGO-MnFe $2 \mathrm{O}_{4} @ \mathrm{Au}-2$ (g). (B): GCE/EDAS/rGO-MnFe $2 \mathrm{O}_{4} @ \mathrm{Au}-1$ (a), GCE/EDAS/rGO-MnFe $2 \mathrm{O}_{4} @ \mathrm{Au}-2$ (b) and GCE/EDAS/rGO-MnFe $2 \mathrm{O}_{4} @ \mathrm{Au}-3$.

oxidation of glucose. The GCE/EDAS/rGO-MnFe ${ }_{2} \mathrm{O}_{4}$ showed poor electrocatalytic response towards glucose oxidation. On the other hand, the Au deposited nanocomposite-modified electrode displayed good electrocatalytic response towards glucose. Figure 4A (e and f) show GCE/EDAS/rGO@Au-2 and GCE/EDAS/ $\mathrm{MnFe}_{2} \mathrm{O}_{4} @ \mathrm{Au}-2$ to be effective for glucose oxidation. However, the surface area and conductivity of $\mathrm{MnFe}_{2} \mathrm{O}_{4}$ is relatively low, which limited its application as support. Significantly, the GCE/EDAS/ rGO- $\mathrm{MnFe}_{2} \mathrm{O}_{4} @ \mathrm{Au}$ (Figure 4A(g)) shows the highest peak current density among the other modified electrodes. The phenomenon indicates that the enhanced catalytic activity of Au NSs on the combination of rGO$\mathrm{MnFe}_{2} \mathrm{O}_{4}$ create a synergistic effect, which achieves an excellent electrocatalytic activity of glucose oxidation.

The mechanism of the glucose direct oxidation is connected to the formation of gold hydroxide sites $\left(\mathrm{Au}[\mathrm{OH}]_{\mathrm{ads}}\right)$ which are formed by chemisorption of hydroxide anion at the $\mathrm{Au} \mathrm{NSs} .{ }^{30} \mathrm{~A}$ small current response was observed in Figure $4 \mathrm{~A}(\mathrm{~g})$ at $-0.47 \mathrm{~V}$ during the positive scan corresponding to the electrosorption of glucose, by releasing one-proton per glucose molecule. ${ }^{31-33}$ The GCE/EDAS/ $/ \mathrm{MnFe}_{2} \mathrm{O}_{4} @ \mathrm{Au}-2$ showed the same signal at the potential of -0.38 . Accompanied by electrosorption of glucose, the accumulation of concomitant intermediates at the electrode surface inhibited the direct oxidation of glucose on the active sites of $\mathrm{Au}$ and hence gave rise to a small anodic current peak at $-0.04 \mathrm{~V}$. At a more positive potential, the oxidation of adsorbed glucose showed an anodic peak at $0.2 \mathrm{~V}$ due to the partial discharge of $\mathrm{OH}^{-}$ from GCE/EDAS/rGO-MnFe ${ }_{2} \mathrm{O}_{4} @ \mathrm{Au}$. However, the formation of gold oxide at a scanning potential above $0.4 \mathrm{~V}$ leads to a decrease in the $\mathrm{Au}[\mathrm{OH}]_{\text {ads }}$ active sites that limited the electrocatalytic activity towards glucose oxidation. In the reverse scan the observed strong oxidation peak near $0.09 \mathrm{~V}$ was associated with the recovery of active $\mathrm{Au}[\mathrm{OH}]_{\text {ads }}$ sites by the reduction of gold oxides and thus glucose can be re-adsorbed and oxidized. ${ }^{34,35}$

The electrocatalytic oxidation of glucose was also performed using the GCE/EDAS/rGO- $\mathrm{MnFe}_{2} \mathrm{O}_{4} @ \mathrm{Au}$ containing different amounts of $\mathrm{Au}(1,2$ and $3 \mathrm{mM})$ concentration. Figure S1 (Supplementary Information) shows the electrochemical performances of GCE/ EDAS/MnFe $\mathrm{O}_{4} @ \mathrm{Au}-1, \mathrm{GCE} / \mathrm{EDAS} / \mathrm{rGO}-\mathrm{MnFe}_{2} \mathrm{O}_{4} @$ $\mathrm{Au}-2$, and GCE/EDAS/rGO-MnFe ${ }_{2} \mathrm{O}_{4} @ \mathrm{Au}-3$ in $0.1 \mathrm{M}$ $\mathrm{NaOH}$ at a scan rate of $50 \mathrm{mV} / \mathrm{s}$. The voltammograms obtained at all the three modified electrodes showed two peaks at $0.43 \mathrm{~V}$ and $0.10 \mathrm{~V}$, due to the presence of Au catalysts. In the absence of glucose, the anodic and cathodic peaks located at about $0.43 \mathrm{~V}$ and $0.10 \mathrm{~V}$ corresponding to the oxidation of gold and subsequent reduction of the gold oxides, respectively. ${ }^{36,37}$ Figure $4 \mathrm{~B}$ shows that the peak current density was further increased when the concentration of $\mathrm{Au}$ increased from $1 \mathrm{mM}$ to $2 \mathrm{mM}$ in the composites, due to the higher catalytic activity of the nanocomposite through the optimum loading of $\mathrm{Au}$ network on EDAS/rGO-MnFe ${ }_{2} \mathrm{O}_{4}$. When the Au concentration 

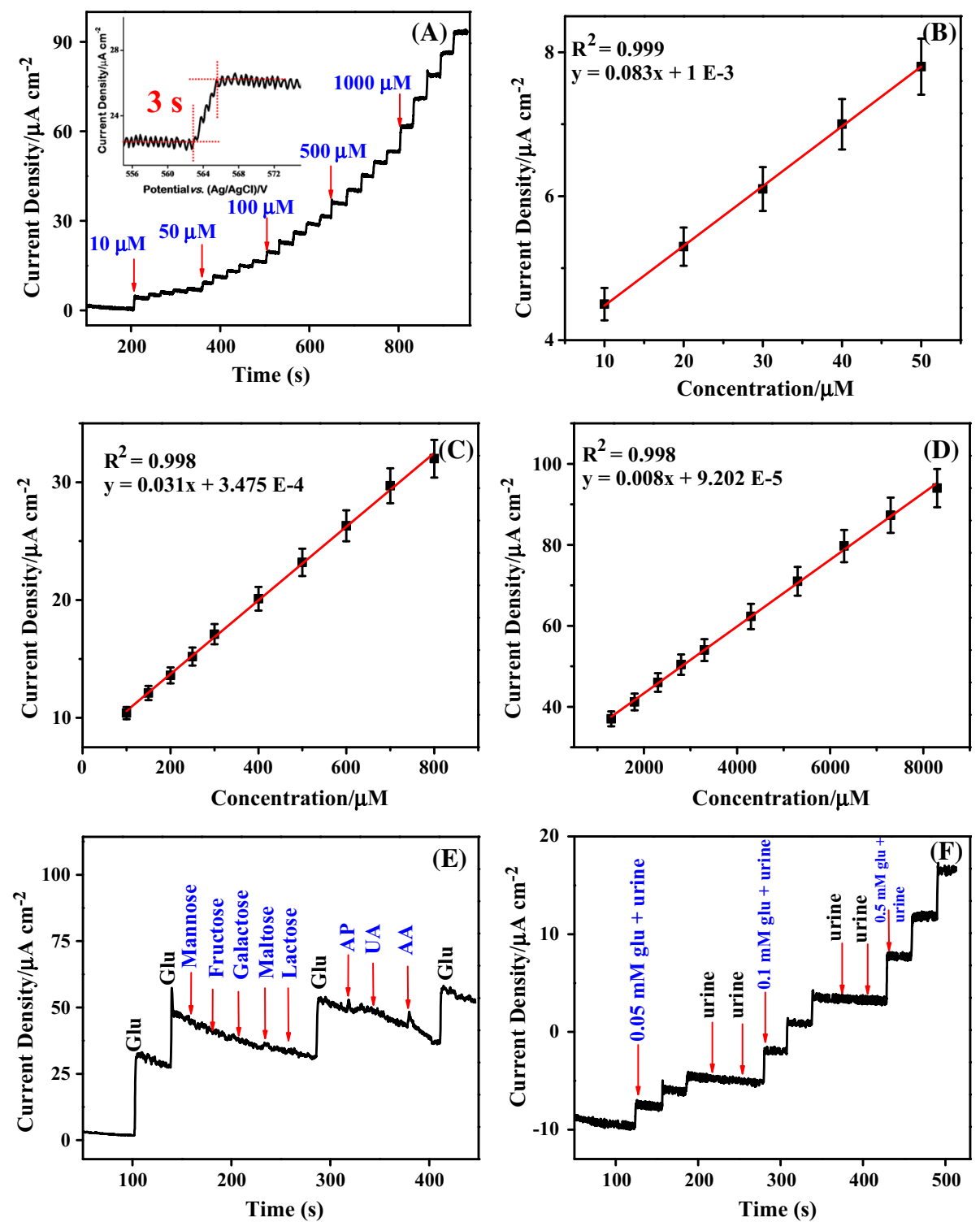

Figure 5. (A) Amperometry response obtained for GCE/EDAS/rGO- $\mathrm{MnFe}_{2} \mathrm{O}_{4} @$ $\mathrm{Au}-2$ upon successive addition of glucose in the concentration range from $10 \mu \mathrm{M}$ to $8.3 \mathrm{mM}$ in $0.1 \mathrm{M} \mathrm{NaOH}$ solution at an applied potential of 0.2 V. Inset: Enlarged view of the i-t response of single addition of $100 \mu \mathrm{M}$ glucose. (B-D): Calibration curves obtained at different concentration addition of glucose: (B) $10 \mu \mathrm{M}$, (C) 50 and 100 $\mu \mathrm{M}$, (D) 500 and $1000 \mu \mathrm{M}$. (E): $0.1 \mathrm{mM}$ of each fructose, mannose, maltose, sucrose, lactose, $0.04 \mathrm{mM}$ uric acid (UA), $0.1 \mathrm{mM}$ acetamidophenol (AP), $0.1 \mathrm{mM}$ ascorbic acid (AA) as well as $1 \mathrm{mM}$ glucose at the potential of $0.2 \mathrm{~V}$. (F): Spike test response obtained at GCE/EDAS/rGO-MnFe $2 \mathrm{O}_{4} @ \mathrm{Au}-2$ for urine samples.

Table 1. Determination of glucose concentration in urine sample $(n=3)$.

\begin{tabular}{lcccc}
\hline Real samples & Added $(\mu \mathrm{M})$ & Found $(\mu \mathrm{M})$ & RSD $(\%)$ & Recovery $(\%)$ \\
\hline Human urine & 50 & 48.05 & 4 & 96 \\
& 100 & 97.54 & 2.5 & 98 \\
& 500 & 502.94 & 2 & 101 \\
\hline
\end{tabular}

further increased to $3 \mathrm{mM}$ the size of Au nanostructures increased, as is evident from the TEM analyses, which decreased the catalytic activity of $\mathrm{Au}$. At the $\mathrm{Au}$ nanocomposite modified electrodes, the current response for glucose oxidation increased with increasing the Au concentration from 1 to $2 \mathrm{mM}$, and a further 
increase of Au concentration decreased the peak current density. Hence, the $2 \mathrm{mM} \mathrm{Au}$ in the nanocomposite (GCE/EDAS/rGO- $\mathrm{MnFe}_{2} \mathrm{O}_{4} @ \mathrm{Au}-2$ ) exhibited higher catalytic current density than the other nanocomposites. The CV recorded at the EDAS/rGO- $\mathrm{MnFe}_{2} \mathrm{O}_{4} @ \mathrm{Au}-$ 2 nanocomposite-modified electrode at different scan rates $\left(25-350 \mathrm{mV} \mathrm{s}^{-1}\right)$ for the oxidation of $5 \mathrm{mM}$ glucose in $0.1 \mathrm{M} \mathrm{NaOH}$ is shown in Figure S2, Supplementary Information. The catalytic peak current density (Figure S2 $(\mathrm{a}, \mathrm{b})$ ) corresponding to glucose oxidation increased with increasing scan rates and the plot of peak current density versus square root of scan rate displayed a linear relation (Figure S3). This observation shows that the electrocatalytic oxidation of glucose at the GCE/EDAS/rGO-MnFe $\mathrm{O}_{4} @ \mathrm{Au}-2$ nanocompositemodified electrode followed a diffusion-controlled process at the modified electrode. Furthermore, the anodic peak potential $\left(\mathrm{E}_{\mathrm{pa}}\right)$ of the reaction is proportional to $\log$ (scan rate) and from this plot, it is possible to estimate the Tafel slope to obtain information on the rate-determining step. The slope of the line was calculated as $62 \mathrm{mV}$ and the Tafel slope ' $\mathrm{b}$ ' was estimated according to the equation $\left(\mathrm{E}_{\mathrm{p}}=(\right.$ blog $v) / 2+$ const, so $b=124 \mathrm{mV}$ ) for the totally irreversible diffusion-controlled process (Figure S2 (inset)). The value of Tafel slope indicates that one-electron transfer process is the rate-limiting step assuming a transfer coefficient of 0.5 for $\alpha .{ }^{38}$ Assuming that the glucose oxidation mechanism is similar to the one described by Fleischmann et al., ${ }^{39}$ the abstraction of a hydrogen atom from the $\alpha$-carbon with electron transfer to the electrode is most preferred rate-determining step for glucose oxidation. The electrochemical stability of the GCE/EDAS/rGO- $\mathrm{MnFe}_{2} \mathrm{O}_{4} @ \mathrm{Au}-2$ dipped in $0.1 \mathrm{M}$ $\mathrm{NaOH}$ was tested by 25 continuous potential cycling between -0.6 and $+0.6 \mathrm{~V}$ in $10 \mathrm{mM}$ glucose at a scan rate of $50 \mathrm{mV} \mathrm{s}^{-1}$ (Figure S4, Supplementary Information). After 25 cycles, the loss in the integrated current density in the CV for GCE/EDAS/rGO- $\mathrm{MnFe}_{2} \mathrm{O}_{4} @ \mathrm{Au}-2$ was only $5 \%$.

3.4b Non-enzymatic electrochemical sensing of glucose: To obtain an optimal amperometric response for glucose, the effect of different applied potentials at the GCE/EDAS/rGO-MnFe ${ }_{2} \mathrm{O}_{4} @ \mathrm{Au}-2$ was investigated. The amperometric response of the electrode at different applied potentials of $0.0 \mathrm{~V}$ and $0.2 \mathrm{~V}$ in the concentration range of $0.5 \mathrm{mM}$ to $6 \mathrm{mM}$ glucose with each addition in $0.1 \mathrm{M} \mathrm{NaOH}$ were studied in Figure S5, Supplementary Information. The oxidation current density of glucose increased sharply and higher current density response was observed at $0.2 \mathrm{~V}$. So the potential of $0.2 \mathrm{~V}$ was chosen as the working potential for

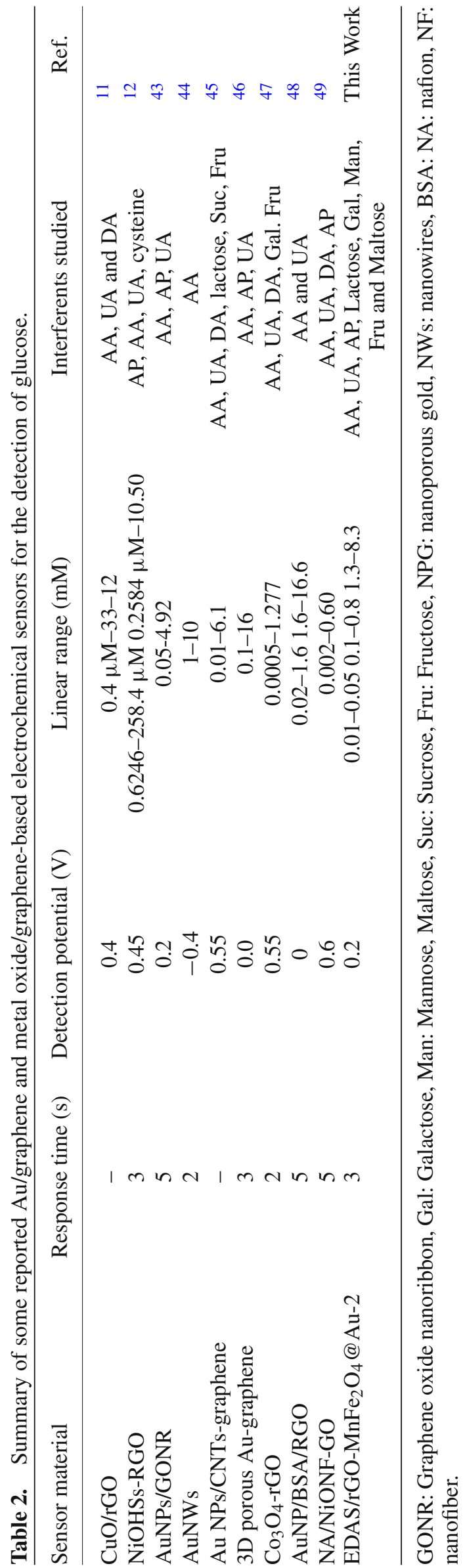


further experiments. The glucose sensing performance was evaluated by the current-time curves for the successive addition of glucose in the concentration range from $10 \mu \mathrm{M}$ to $8 \mathrm{mM}$ which were recorded at an applied potential of $0.2 \mathrm{~V}$. An enhanced current density response was observed as shown in Figure 5A due to the presence of Au NSs deposited on rGO- $\mathrm{MnFe}_{2} \mathrm{O}_{4} \cdot{ }^{40}$ The electrocatalytic activity of rGO-MnFe $\mathrm{O}_{4} @$ Au nanocomposite is considered as a result of the combination of three factors: First, it is the catalytic activity of Au NSs. Second, the rGO provides good electrical conductivity and acts as a support for the $\mathrm{MnFe}_{2} \mathrm{O}_{4}$ and $\mathrm{Au}$ material. Because of the abundant oxygen-containing functional groups, large numbers of homogeneous $\mathrm{MnFe}_{2} \mathrm{O}_{4}$ and $\mathrm{Au}$ NSs can be formed on the surface of rGO sheets. ${ }^{41}$ Finally, after the modification of $\mathrm{MnFe}_{2} \mathrm{O}_{4}$ on GO, they provide an extra surface area to attach more $\mathrm{Au}$ NSs. ${ }^{42}$ Therefore, rGO-MnFe ${ }_{2} \mathrm{O}_{4} @ \mathrm{Au}$ would induce more electroactive sites for the catalytic oxidation reaction of glucose. The proposed sensor showed multilinear detection ranges from different sensitivities up to 50, 700 and $8300 \mu \mathrm{M}$, respectively (Figure 5(B-D)). The limit of detection (LOD) was estimated at $2.0 \mu \mathrm{M}$ using the formula $\mathrm{LOD}=3 \sigma /$ slope and the sensitivity of the modified electrode was found to be $83 \mu \mathrm{A} \mathrm{cm}^{-2} \mathrm{mM}^{-1}$ for glucose detection. It should be noted that a response time of $3 \mathrm{~s}$ to attain steady-state current density was observed.

To ensure the selectivity of the developed sensor for glucose, the GCE/EDAS/rGO- $\mathrm{MnFe}_{2} \mathrm{O}_{4} @ \mathrm{Au}-2$ was evaluated in the presence of common interferents at an applied potential of $0.2 \mathrm{~V}$. The common interference species such as fructose, mannose, maltose, lactose, uric acid, acetamidophenol and ascorbic acid were studied. The addition of acetamidophenol, ascorbic acid to $1 \mathrm{mM}$ glucose solution resulted in a sharp increase in the current density response and did not interfere with the glucose detection (Figure 5E). In order to detect the practical applicability, the designed GCE/EDAS/rGO$\mathrm{MnFe}_{2} \mathrm{O}_{4} @ \mathrm{Au}-2$ was tested to determine glucose in human urine samples. The urine samples were diluted 10 times using $0.1 \mathrm{M} \mathrm{NaOH}$ and used. Figure $5 \mathrm{~F}$ shows the current density-time curves for the successive additions of glucose standard solution mixed with the urine sample. Table 1 shows a high recovery of glucose with the relative standard deviation (RSD\%) value in the range from 2 to 4 . The linear range of glucose detection and the applied potential were compared with the recent reports and summarized in Table 2. Compared to the previous reports, the present sensor offered better electrocatalytic performance with a wide detection range and low applied potential.

\section{Conclusions}

In the present work, EDAS/rGO- $\mathrm{MnFe}_{2} \mathrm{O}_{4} @ \mathrm{Au}$ nanocomposite has been synthesized and characterized. The GCE/EDAS/rGO- $\mathrm{MnFe}_{2} \mathrm{O}_{4} @ \mathrm{Au}-2$ nanocomposite exhibited the best electrocatalytic response towards glucose oxidation in $0.1 \mathrm{M} \mathrm{NaOH}$ solution when compared to other catalyst studied. The enhanced electrochemical behavior is mainly attributed to the optimized loading of $\mathrm{Au} \mathrm{NSs}$ on $\mathrm{rGO}-\mathrm{MnFe}_{2} \mathrm{O}_{4}$ nanocomposite and its catalytic properties. The EDAS/rGO- $\mathrm{MnFe}_{2} \mathrm{O}_{4} @ \mathrm{Au}-2$ modified electrode displays good selectivity, good sensitivity $\left(83 \mu \mathrm{A} \mathrm{cm}^{-2} \mathrm{mM}^{-1}\right)$ and low detection limit $(2 \mu \mathrm{M})$. The GCE/EDAS/rGO- $\mathrm{MnFe}_{2} \mathrm{O}_{4} @ \mathrm{Au}-2$ was successfully applied to detect glucose in urine sample indicating that the GCE/EDAS/rGO- $\mathrm{MnFe}_{2} \mathrm{O}_{4} @ \mathrm{Au}-2$ based non-enzymatic glucose sensor has a great potential in real sample analysis.

\section{Supplementary Information}

The details of the Synthesis of $\mathrm{rGO} / \mathrm{MnFe}_{2} \mathrm{O}_{4}$ nanocomposite and Figures S1-S5 are available at www.ias.ac.in/chemsci.

\section{Acknowledgements}

RR acknowledges the (No. 21(1006)/15/EMR-II) Council of Scientific and Industrial Research-Emeritus Scientist Scheme for financial support. TRM is the recipient of DST-INSPIRE Senior Research Fellowship (No. IF150326).

\section{References}

1. Vignesh R H, Sankar K V, Amaresh S, Lee Y S and Selvan R K 2015 Synthesis and characterization of $\mathrm{MnFe}_{2} \mathrm{O}_{4}$ nanoparticles for impedometric ammonia gas sensor Sens. Actuat. B 22050

2. Zhu H, Zhang S, Huang Y, Wu L and Sun S 2013 Monodisperse $\mathrm{M}_{x} \mathrm{Fe}_{3-x} \mathrm{O}_{4}(\mathrm{M}=\mathrm{Fe}, \mathrm{Cu}, \mathrm{Co}, \mathrm{Mn})$ nanoparticles and their electrocatalysis for oxygen reduction reaction Nano Lett. 132947

3. Albuquerque A S, Tolentino M V C, Ardisson J D, Moura F C C, Mendonça R and Macedo W A A 2012 Nanostructured ferrites: Structural analysis and catalytic activity Ceram. Int. 382225

4. Li Y, Shen J, Hu Y, Qiu S, Min G, Song Z, Sun Z and $\mathrm{Li} \mathrm{C} 2015$ General flame approach to chainlike $\mathrm{MFe}_{2} \mathrm{O}_{4}$ spinel $(\mathrm{M}=\mathrm{Cu}, \mathrm{Ni}, \mathrm{Co}, \mathrm{Zn})$ nanoaggregates for reduction of nitroaromatic compounds Ind. Eng. Chem. Res. 54 9750

5. Mathew D S and Juang R 2007 An overview of the structure and magnetism of spinel ferrite nanoparticles and their synthesis in microemulsions Chem. Eng. J. 12951

6. Xiao Y, Zai J, Tao L, Li B, Han Q, Yu C and Qian X $2013 \mathrm{MnFe}_{2} \mathrm{O}_{4}$-graphene nanocomposites with enhanced performances as anode materials for Li-ion batteries Phys. Chem. Chem. Phys. 153939 
7. Salamon J, Sathishkumar Y, Ramachandran K, Lee Y S, Yoo D J, Kim A R and Gnana Kumar G 2015 One-pot synthesis of magnetite nanorods/graphene composites and its catalytic activity toward electrochemical detection of dopamine Biosens. Bioelectron. 64269

8. Guo S, Zhang G, Guo Y and Yu J C 2013 Graphene oxide- $\mathrm{Fe}_{2} \mathrm{O}_{3}$ hybrid material as highly efficient heterogeneous catalyst for degradation of organic contaminants Carbon 60437

9. Geim A K and Novoselov K S 2007 The rise of graphene Nat. Mater. 6183

10. Zhu Y, Murali S, Cai W, Li X, Suk J W, Potts J R and Ruoff R S 2010 Graphene and graphene oxide: Synthesis, properties, and applications Adv. Mater. 223906

11. Wang X, Liu E and Zhang X 2014 Non-enzymatic glucose biosensor based on copper oxide-reduced graphene oxide nanocomposites synthesized from water isopropanol solution Electrochim. Acta 130253

12. Lu P, Yu J, Lei Y, Lu S, Wang C, Liu D and Guo Q 2015 Synthesis and characterization of nickel oxide hollow spheres-reduced graphene oxide-nafion composite and its biosensing for glucose Sens. Actuat. B Chem. 20890

13. Dong $\mathrm{X}, \mathrm{Xu} \mathrm{H}$, Wang $\mathrm{X}$, Huang $\mathrm{Y}$, Chan-Park M B, Zhang H, Wang L, Huang W and Chen P 2012 3D graphene cobalt oxide electrode for high-performance supercapacitor and enzymeless glucose detection ACS Nano 63206

14. Bharathi S, Fishelson N and Lev O 1999 Direct synthesis and characterization of gold and other noble metal nanodispersions in sol-gel-derived organically modified silicates Langmuir 151929

15. Rameshkumar P, Viswanathan P and Ramaraj R 2014 Silicate sol-gel stabilized silver nanoparticles for sensor applications toward mercuric ions, hydrogen peroxide and nitrobenzene Sens. Actuat. B Chem. 2021070

16. Manivannan S and Ramaraj R 2012 Synthesis of cyclodextrin-silicate sol-gel composite embedded gold nanoparticles and its electrocatalytic application Chem. Eng. J. 210195

17. Jena B K and Raj C R 2006 Enzyme-free amperometric sensing of glucose by using gold nanoparticles Chem. A Eur. J. 122702

18. Hoa L T, Chung J S and Hur S H 2016 A highly sensitive enzyme-free glucose sensor based on $\mathrm{Co}_{3} \mathrm{O}_{4}$ nanoflowers and 3D graphene oxide hydrogel fabricated via hydrothermal synthesis Sens. Actuat. B Chem. 223 76

19. Tian K, Prestgard M and Tiwari A 2014 A review of recent advances in nonenzymatic glucose sensors Mater. Sci. Eng. C $\mathbf{4 1} 100$

20. Marcano D C, Kosynkin D V, Berlin J M, Sinitskii A, Sun Z, Slesarev A, Alemany L B, Lu W and Tour J M 2010 Improved synthesis of graphene oxide ACS Nano 44806

21. Guo P, Zhang G, Yu J, Li H and Zhao X S 2012 Controlled synthesis, magnetic and photocatalytic properties of hollow spheres and colloidal nanocrystal clusters of manganese ferrite Colloids Surf. A Physicochem. Eng. Asp. 395168

22. Jakhmola A, Celentano M, Vecchione R, Manikas A, Battista E, Calcagno V and Netti P A 2017 Self-assembly of gold nanowire networks into gold foams: Production, ultrastructure and applications Inorg. Chem. Front. 4 1033

23. Bai R G, Muthoosamy K, Zhou M, Ashokkumar M, Huang N M and Manickam S 2017 Sonochemical and sustainable synthesis of graphene-gold (G-Au) nanocomposites for enzymeless and selective electrochemical detection of nitric oxide Biosens. Bioelectron. 87622

24. Neogy R K, Nath R and Raychaudhuri A K 2017 Thermal transport enhancement in gold nanofluid containing network like structure Mater. Chem. Phys. 186478

25. Yi Z, Luo J, Tan X, Yi Y, Yao W, Kang X, Ye X, Zhu W, Duan T, Yi Y and Tang Y 2015 Mesoporous gold sponges: Electric charge-assisted seed mediated synthesis and application as surface-enhanced Raman scattering substrates Sci. Rep. 516137

26. Zha D, Xiong P and Wang X 2015 Strongly coupled manganese ferrite/carbon black/polyaniline hybrid for low-cost supercapacitors with high rate capability Electrochim. Acta $\mathbf{1 8 5} 218$

27. Rameshkumar P, Praveen R and Ramaraj R 2015 Electroanalysis of oxygen reduction and formic acid oxidation using reduced graphene oxide/gold nanostructures modified electrode J. Electroanal. Chem. 754118

28. Nurzulaikha R, Lim H N, Harrison I, Lim S S, Pandikumar A, Huang N M, Lim S P, Thien G S H, Yusoff $\mathrm{N}$ and Ibrahim I 2015 Graphene/SnO 2 nanocompositemodified electrode for electrochemical detection of dopamine Sens. Bio Sens. Res. 542

29. Thanh T D, Balamurugan J, Hwang J Y, Kim N H and Lee J H 2016 In situ synthesis of graphene-encapsulated gold nanoparticle hybrid electrodes for non-enzymatic glucose sensing Carbon 9890

30. Bai Y, Yang W, Sun Y and Sun C 2008 Enzyme-free glucose sensor based on a three-dimensional gold film electrode Sens. Actuat. B Chem. 134471

31. Wang J, Cao X, Wang X, Yang S and Wang R 2014 Electrochemical oxidation and determination of glucose in alkaline media based on $\mathrm{Au}(111)$-like nanoparticle array on indium tin oxide electrode Electrochim. Acta 138174

32. Lang X Y, Fu H Y, Hou C, Han G, Yang P, Liu Y and Jiang Q 2013 Nanoporous gold supported cobalt oxide microelectrodes as high-performance electrochemical biosensors Nat. Commun. 42169

33. Kong F Y, Li X R, Zhao W W, Xu J J and Chen H C 2012 Graphene oxide-thionine-Au nanostructure composites: Preparation and applications in non-enzymatic glucose sensing Electrochem. Commun. 1459

34. Karra S, Wooten M, Griffith W and Gorski W 2016 Morphology of gold nanoparticles and electrocatalysis of glucose oxidation Electrochim. Acta 2188

35. Soomro R A, Akyuz O P, Ozturk R and Ibupoto Z H 2016 Highly sensitive non-enzymatic glucose sensing using gold nanocages as efficient electrode material Sens. Actuat. B Chem. 233230

36. Matsumoto F, Harada M, Koura N and Uesugi S 2003 Electrochemical oxidation of glucose at $\mathrm{Hg}$ adatommodified $\mathrm{Au}$ electrode in alkaline aqueous solution Electrochem. Commun. 542

37. Luo Y, Kong F, Li C, Shi J, Lv W and Wang W 2016 One-pot preparation of reduced graphene oxide-carbon 
nanotube decorated with $\mathrm{Au}$ nanoparticles based on protein for non-enzymatic electrochemical sensing of glucose Sens. Actuat. B Chem. 234625

38. Cherevko $\mathrm{S}$ and Chung $\mathrm{C} 2010$ The porous $\mathrm{CuO}$ electrode fabricated by hydrogen bubble evolution and its application to highly sensitive non-enzymatic glucose detection Talanta $\mathbf{8 0} 1371$

39. Fleischmann M, Korinek K and Pletcher D 1972 The kinetics and mechanism of the oxidation of amines and alcohols at oxide-covered nickel, silver, copper, and cobalt electrodes J. Chem. Soc. Perkin. Trans. 21396

40. Shu H, Chang G, Su J, Cao L, Huang Q, Zhang Y, Xia T and He Y 2015 Single-step electrochemical deposition of high performance Au-graphene nanocomposites for nonenzymatic glucose sensing Sens. Actuat. B 220331

41. Hu Y, Jin J, Wu P, Zhang H and Cai C 2010 Graphenegold nanostructure composites fabricated by electrodeposition and their electrocatalytic activity toward the oxygen reduction and glucose oxidation Electrochim. Acta $\mathbf{5 6} 491$

42. Bai W, Nie F, Zheng J and Sheng Q 2014 Novel silver nanoparticle-manganese oxyhydroxide-graphene oxide nanocomposite prepared by modified silver mirror reaction and its application for electrochemical sensing ACS Appl. Mater. Interfaces 65439

43. Ismail N S, Le Q H, Yoshikawa H, Saito M and Tamiya E 2014 Development of non-enzymatic electrochemical glucose sensor based on graphene oxide nanoribbongold nanoparticle hybrid Electrochim. Acta 14698

44. Cherevko S and Chung C 2009 Gold nanowire array electrode for non-enzymatic voltammetric and amperometric glucose detection Sens. Actuat. B Chem. 142216

45. Fu S, Fan G, Yang L and Li F 2015 Non-enzymatic glucose sensor based on Au nanoparticles decorated ternary $\mathrm{Ni}-\mathrm{Al}$ layered double hydroxide/single-walled carbon nanotubes/graphene nanocomposite Electrochim. Acta 152146

46. Shu H, Chang G, Su J, Cao L, Huang Q, Zhang Y, Xia T and He Y 2015 Single-step electrochemical deposition of high performance Au-graphene nanocomposites for nonenzymatic glucose sensing Sens. Actuat. B Chem. 220331

47. Zheng Y, Li P, Li H and Chen S 2014 Controllable growth of cobalt oxide nanoparticles on reduced graphene oxide and its application for highly sensitive glucose sensor Int. J. Electrochem. Sci. 97369

48. Liu Y, Dong Y, Guo C X, Cui Z, Zheng L and Li C M 2012 Protein-directed in situ synthesis of gold nanoparticles on reduced graphene oxide modified electrode for nonenzymatic glucose sensing Electroanalysis $\mathbf{2 4}$ 2348

49. Zhang Y, Wang Y, Jia J and Wang J 2012 Nonenzymatic glucose sensor based on graphene oxide and electrospun NiO nanofibers Sens. Actuat. B 171580 